九州大学学術情報リポジトリ

Kyushu University Institutional Repository

\title{
Tannic Acid Enhancing Insecticidal Activity of Protoxin Produced in Bacillus thuringiensis subsp. Kurstaki KB100 Strain Against Spodoptera exigua
}

Jin, Na Young

Department of Applied Biology, College of Agriculture and Life Sciences, chungnam National University

Lee, You Kyoung

Department of Applied Biology, College of Agriculture and Life Sciences, chungnam National University

\section{Lee, Bo Ram}

Department of Applied Biology, College of Agriculture and Life Sciences, chungnam National University

Kim, Yu Seop

Department of Applied Biology, College of Agriculture and Life Sciences, chungnam National University

他

https://doi.org/10.5109/1526296

出版情報：九州大学大学院農学研究院紀要. 60 (1)，pp.97-102，2015-02-27. Faculty of Agriculture， Kyushu University

バージョン :

権利関係 : 


\title{
Tannic Acid Enhancing Insecticidal Activity of Protoxin Produced in Bacillus thuringiensis subsp. Kurstaki KB100 Strain Against Spodoptera exigua
}

\author{
Na Young JIN ${ }^{1}$, You Kyoung LEE ${ }^{1}$, Bo Ram LEE ${ }^{1}$, Yu Seop KIM ${ }^{1}$, Jun Hack JUN ${ }^{1}$, \\ Mi Ja SEO ${ }^{1}$, Young Nam YOUN ${ }^{1}$, Chisa YASUNAGA-AOKI ${ }^{2 *}$ \\ and Yong Man YU'*
}

\author{
Laboratory of Insect Pathology and Microbial Control, Institute of Biological Control, \\ Faculty of Agriculture, Kyushu University, Fukuoka 812-8581, Japan \\ (Received October 30, 2014 and accepted November 14, 2014)
}

\begin{abstract}
Insecticidal activity was enhanced when Bacillus thuringiensis subsp. kurstaki KB100 strain containing insecticidal activity against Spodoptera exigua was mixed with tannic acid, a protease inhibitor. To investigate the cause of this result, inhibition rate of tannic acid against protease activity in midgut juice of $S$. exigua was measured. As a result, it was found that protease activity in midgut juice of $S$. exigua was about $83.1 \%, 77.6 \%, 68.0 \%$, and $40.1 \%$ at concentrations of $10,20,40$ and $80 \mathrm{mM}$, respectively. Such reduction of protease activity was measured with increasing concentration. Analysis of substrate reaction in several kinds of proteases was performed. Trypsin exhibited $91.4 \%$ and $89.4 \%$ of proteolytic activity in BApNA and BPVApNA substrates, respectively. Thus, when Trypsin was treated with tannic acid, proteolytic activity was 62.2\% and 54.5\% in BApNA and BPVApNA substrates, respectively. Trypsin's proteolytic activity was inhibited by $29.2 \%$ and $34.9 \%$ when mixed with tannic acid. However, proteolytic activity of chymotrypsin and elastase was not inhibited by tannic acid. Digestion of protoxin produced in B. thuringiensis KB100 strain by Trypsin was analyzed using SDS-PAGE. As a result, a band appeared at about $60 \mathrm{kDa}-70 \mathrm{kDa}$ and it seemed to be inhibited by tannic acid. Digestion patterns of protoxin were measured over time. As it was over-digested in a group of Trypsin treatment, a band of protoxin at $60 \mathrm{kDa}$ completely disappeared. On the other hand, when it was treated with tannic acid, a digestion inhibitor, protoxin was maintained for up to 24 hours.
\end{abstract}

Key words: Bacillus thuringiensis KB100 strain, proteolytic enzymes, Spodoptera exigua, tannic acid

\section{INTRODUCTION}

Spodoptera exigua is classified as Order Lepidoptera, Family Noctuidae and Genus Spodoptera and it is the most common agricultural pest which is the most difficult one to control as a polyphagous pest (Ahn et al., 1989). Since $S$. exigua has a broad range of hosts, it gives a lot of damage to a variety of crops such as scallion, cabbage and watermelon (Park et al., 1991). As $S$. exigua is rapidly spread out after it passes the third stage and generations are mixed, it is the pest which is difficult one to control during packaging (Luo et al., 2000). Chemical insecticides such as organophosphate, carbamate and pyrethroid insecticides are being used to control this pest (Eveleens et al., 1973). However, S. exigua has a high resistance to most of commercially available insecticides (Noh, 2009). Moreover, larvae with increasing age exhibit significantly low sensitivity to chemical insecticides. On the other hand, the use of microbial insecticides is recently demanded for ecofriendly agriculture, but it is difficult to control this pest due to physiological and ecological characteristics of $S$. exigua and mixture of generation during packaging.

Dept. Applied Biology, College of Agriculture and Life Sciences, chungnam National University, Daejon 305-764, Korea

${ }^{2}$ Laboratory of Insect Pathology and Microbial Control, Institute of Biological Control, Faculty of Agriculture, Kyushu University

* Joint corresponding authors (E-mail: ymyu@cnu.ac.kr; yasunaga@grt.kyushu-u.ac.jp)
Because $B$. thuringiensis agent being used as a microbial insecticide to control $S$. exigua in Korea exhibits low control threshold, effective studies on use methods and treatment time are needed (Jin et al., 2009).

$B$. thuringiensis which is a microbial insecticide produces insecticidal crystal proteins (ICPs) which are called $\delta$-endotoxin during the formation of spores (Schnepf et $a l .$, 1998; Kumar 2003). These ICPs consist of Cry proteins which have activity against Lepidoptera (CryI), Lepidoptera and Diptera (CryII), Coleoptera (CryIII), Diptera (CryIV), and Lepidoptera and Coleoptera (CryV) (De Maagd et al., 2003; Schnepf et al., 1998; van Frankenhuyzen, 2009). ICPs are produced by B. thuringiensis and their molecular weight is $130 \mathrm{kDa}$. However, it does not have insecticidal activity in steady state. It exhibits activity if it is hydrolyzed into proteins at $55-70 \mathrm{kDa}$ by proteolytic enzymes in midgut juice once larvae eat it. Activated toxin acts on epithelial cells of midgut in larvae and punches the hole in the membrane. In final, it becomes toxin and kills insects (Soberon et al., 2009).

Enzymes digest insecticidal toxin proteins which kill lepidopteran pests and consist of three groups such as serine proteinases, cysteine proteinases and aspartic proteinases. It is known that proteolytic enzymes such as serine proteinases and cysteine proteinases are present in midgut juice of $S$. exigua (Jongsma, 1996). It has been known that proteases are the most important digestive enzymes in insecticidal activity of $B$. thuringiensis and 
serine proteases such as trypsin and chymotrypsin play a major role in the process of protein hydrolysis (Tojo and Aizawa, 1983; Zhu et al., 2007). It has been reported that trypsin and chymotrypsin are the most important digestive enzymes to activate protoxin in midgut of $B$. thuringiensis and play an important role to digest ICPs (Zhu et al., 2007; Opprert, 1999).

In previous studies, new B. thuringiensis containing strong activity against $S$. exigua was selected and tannic acid was selected as one of protease inhibitor which could prevent the over-digestion of protoxin of B. thuringiensis caused by strong digestive activity of midgut juice of pests (Jin et al., 2009). It was confirmed that addition of tannic acid into $B$. thuringiensis resulted in increase of activity (Jin et al., 2009). In addition, it has been reported that Tannis reduces the amount of strains eaten by larvae and enhances insecticidal activity of $B$. thuringiensis (Lord and Undeen, 1990; Navon et al., 1993). According to Salama et al. (1984), tannic acid increased the efficacy of $\delta$-endotoxin by $2-4$ folds and it increased $\mathrm{pH}$ in midgut of insects, resulting in increase of insecticidal activity of $B$. thuringiensis once tannic acid was added (Schnepf et al., 1998). However, mechanism of interaction between $B$. thuringiensis and tannic acid has not been clearly known yet. It has been reported that Tannins inhibited activity of proteases and thus inhibited growth of lepidopteran larvae (Chan et al., 1978; Klocke and Chan, 1982; Karowe, 1989; Morris et al., 1995).

In this study, we reviewed the mechanism of synergistic effects on interaction between $B$. thuringiensis showing activity against $S$. exigua. In addition, we sought the methods to effectively control $S$. exigua by examining the effects of treatment of tannic acid on inhibition of capacity of digestive enzymes which hydrolyzes protoxin of $B$. thuringiensis strain.

\section{MATERIALS AND METHODS}

\section{Test insects}

S. exigua used in this experiment was given by the insect physiology laboratory in Andong National University and artificial diet (Goh et al., 1990) was used for all insects being cultured over successive generations in the biological pest control laboratory in Chungnam National University. Culture conditions are as follows: Temperature of $25 \pm 1^{\circ} \mathrm{C}$, light conditions of 16L:8D. Adults were fed on 10\% sugar water.

\section{Test $B$. thuringiensis strain}

Among $B$. thuringiensis strains isolated from domestic soils and being stored in the laboratory, we selected KB100 strain showing a synergistic effect when mixed with Tannic acid and we performed experiment. We sent it to Dr. M. Obha in Institute of Biological Control, Faculty of Agriculture, Kyusu University, Fukuoka, Japan to identify it. As a result of $\mathrm{H}$ serotype, it was identified as B. thuringiensis subsp. Kurstaki.

\section{Preparation of midgut juice of $\boldsymbol{S}$. exigua}

Midgut juice was prepared to digest protoxin of $B$. thuringiensis as follows. After larvae of $S$. exigua at the fifth stage were placed at $-4^{\circ} \mathrm{C}$ for 10 seconds, midgut was dissected by using a sterile dissecting blade and put in a centrifugation tube on ice. It was centrifuged at 13,000 rpm for 15 minutes. Only light brown supernatant was transferred into a new eppendorf tube and stored at $-20^{\circ} \mathrm{C}$.

\section{Preparation of Parasporal crystal, Tannic acid, Trypsin and Chymotrypsin}

For preparation of parasporal crystal, B. thuringiensis strain was inoculated into NA media and incubated at $27^{\circ} \mathrm{C}$ for 5 days and then occurrence of autolysis was examined with a phase contrast microscope. Once it was confirmed, it was transferred into a centrifuge tube with PBS buffer and then centrifuged at $15,000 \mathrm{rpm}$ at $4^{\circ} \mathrm{C}$ for 10 minutes. After centrifugation, the supernatant was discarded and it was washed three times with washing buffer I ( $500 \mathrm{mM} \mathrm{NaCl}, 2 \%$ Triton $\mathrm{X}-100)$. It was washed twice with washing buffer II (500 mM NaCl). After sterile water was added, washed parasporal inclusion was stored at $-20^{\circ} \mathrm{C}$ until it was used. Tannic acid (Sigma Co.) was diluted into four kinds of concentration $(0.4,4,40$ and $80 \mathrm{mM} / \mathrm{l})$ using distilled water. $1 \mathrm{mg} / \mathrm{ml}$ Trypsin (Sigma Co.) and chymotrypsin (Sigma Co.) were used as proteases to examine the role of tannic acid as a protease inhibitor.

\section{SDS-PAGE}

Parasporal inclusion of $B$. thuringiensis was dissolved in $50 \mathrm{mM} \mathrm{NaOH}$ (pH12.5). To observe the inhibitory phenomenon over time, $7 \mu \mathrm{l}$ parasporal inclusion of $B$. thuringiensis and $2 \mu \mathrm{l}$ midgut juice of $S$. exigua were added and digested at $37^{\circ} \mathrm{C}$ for 15 minutes. After $2 \mu \mathrm{l}$ of $40 \mathrm{mM}$ tannic acid was added, it was incubated at each time point (1 minute, 5 minutes, 10 minutes, 15 minutes, 30 minutes, 1 hour, 2 hours, 5 hours and 24 hours) at $37^{\circ} \mathrm{C}$ and used in the experiment. Parasporal inclusion was incubated at $37^{\circ} \mathrm{C}$ for 30 minutes, after it was treated with $10 \mu \mathrm{l}$ of trypsin $(0.1 \mathrm{mg} / \mathrm{ml})$ and $1 \mu \mathrm{l}$ chymotrypsin $(0.1 \mathrm{mg} / \mathrm{ml}) .10 \mu \mathrm{l}$ parasporal inclusion, $1 \mu \mathrm{l}$ Trypsin and $1 \mu \mathrm{l}$ of $40 \mathrm{mM}$ tannic acid were treated. For SDS-PAGE, a gel was made with $12 \%$ separating gel and 5\% stacking gel according to the modified method of Laemmli (1970). After the electrophoresis was finished, a gel was stained with 0.5\% Coomassie Brilliant Blue.

\section{Measurement of protease activity of $S$. exigua}

To measure protease activity, a method of Bradford (1976) was modified and used in this experiment. To measure activity of each digestive enzyme, substrates were used as follows: N- $\alpha$-Benzoyl-DL-arginine 4-nitroanilide hydrochloride (BApNA) and N-BenzoylPhe-Val-Arg-p-nitroanilide hydrochlorid (BPVApNA) were used as substrates for trypsin. N-Benzoyl-Ltyrosine p-nitroanilide (BTpNA) and N-Succinyl-AlaAla-Pro-Phe p-nitroanilide (SAAPPpNA) and Ala-AlaVal-Ala p-nitroanilide (AAVApNA) were used as sub- 
strates for chymotrypsin. N-Succinyl-Ala-Ala-Ala-pnitroanilide (SAAApNA) and N-Succinyl-Ala-Ala-ProLeu p-nitroanilide (SAAPLpNA) were used as substrates for elastase. To determine the inhibitory capacity of tannic acid against midgut juice of $S$. exigua, azocasein was used as a substrate at various concentrations (10, 20, 40 and $80 \mathrm{mM} / \mathrm{l})$. After midgut juice of $S$. exigua and tannic acid were mixed in the ratio of $1: 1$, it was incubated at $37^{\circ} \mathrm{C}$ for 15 minutes. After $300 \mu \mathrm{l}$ of each substrate was mixed with $100 \mu$ l of digested sample, it was incubated at $37^{\circ} \mathrm{C}$ for 15 minutes. The reaction was stopped by adding $200 \mu \mathrm{l}$ of $10 \%$ TCA. After the sample was centrifuged at $15,000 \mathrm{rpm}$ at $4^{\circ} \mathrm{C}$ for 30 minutes, supernatant was mixed with $1 \mathrm{M} \mathrm{NaOH}$ in the ratio of $1: 1$ to precipitate proteins. After that, protein concentration was measured by absorbance at $450 \mathrm{~nm}$.

\section{RESULTS AND DISCUSSION}

\section{Protoxin of B. thuringiensis KB100 strain of which insecticidal activity is reduced due to over-diges- tion in midgut juice of $S$. exigua}

As eggs of $S$. exigua are laid and stuck as egg rafts in crops, it is difficult to biologically control them. Larvae live together once they hatch eggs. Once they pass the third stage, they begin spreading out and hiding to live. Thus, it is more difficult to control them. Due to the physiological and ecological characteristics of this pest in which adults continue to fly in from neighboring areas and lay eggs, it is one of most difficult pests to be controlled in the farm. B. thuringiensis is most commonly used to biologically control $S$. exigua occurring in organic crops and it shows very various insecticidal activities depending on its strains. Thus, in a previous study by Jin et al. (2009), the synergistic effect of B. thuringiensis mixed with tannic acid on insecticidal activity was examined. It was found that a group mixed with $B$. thuringiensis and tannic acid showed a higher extinction rate than a group treated with $B$. thuringiensis alone. Therefore, we reviewed mechanisms which may occur in the relationship between protoxin and digestive enzymes of midgut juice of $S$. exigua to increase the control effect. Five kinds such as tannic acid, PMSF, EDTA, TLCK and SBTI were selected as protease inhibitors containing the highest activity to inhibit digestive enzymes of midgut juice in $S$. exigua. As a result of measuring activity of five kinds of protease inhibitors against midgut juice of $S$. exigua, it was found tannic acid constantly inhibited activity of protease in midgut juice of $S$. exigua (Jin et al., 2009). To determine the most optimal activity reaction of tannic acid with protease present in midgut, it was measured at various concentrations. As shown in Table 1, protease activity of midgut of $S$. exigua was inhibited in about $83.1 \%, 77.6 \%, 68.0 \%$ and $40.1 \%$ with increasing concentration of tannic acid such as 10, 20, 40 and $80 \mathrm{mM}$, respectively. Through above results, we could expect that protease activity of midgut of $S$. exigua was effectively inhibited with increasing the concentration of Tannic acid. In addition, according to Ananthakrishnan et al. (1990), weight and survival rate of pupae were measured after giving foods of $H$. armigera treated with tannic acid at various concentrations. As a result, the weight of pupae feeding foods mixed with tannic acid got lighter and the survival rate got lower than those of pupae feeding regular foods. The reason was that foods were not digested because protease activity of midgut of larvae was inhibited by Tannic acid.

Proteases present in midgut of $S$. exigua consist of serine proteases such as Trypsin, chymotrypsin and elastase (Opprert, 1999). It was reported that the use of high substrate specificity was appropriate to determine the characteristics of digestive enzymes (Law et al., 1977). Thus, we measured activity of proteases after the reaction was performed by adding the specific substrate for proteases present in midgut of $S$. exigua in this experiment. If protease activity was measured by using azocasein which was a substrate for serine proteases as a control, the activity was $100 \%$. As shown in Table 2, when protease activity was measured by using a substrate for Trypsin, activity was about $90 \%$ or higher. On the other hands, when it was measured by using a substrate for chymotrypsin, activity was about 55\%, which was lower than that of trypsin by about 35\%. Activity of elastase was about 44\%, which was the lowest among three kinds of proteases. Through this result, we could expect that trypsin had the highest activity among proteases in midgut of $S$. exigua. According to results of a previous study showing the inhibition of protease activity in midgut juice of $S$. exigua, we performed the reaction treated with tannic acid. Tannic acid selected as an activity inhibitor was prepared at four kinds of concentration $(10,20,40$ and $80 \mathrm{mM} / \mathrm{l})$. After it was mixed with midgut juice of $S$. exigua, we measured the degree of inhibition in activity of proteases (Table 3). As a result, when midgut juice was reacted with substrates for Trypsin such as BApNA and BPVApNA, activity was $91.4 \pm 1.8$ and $89.4 \pm 0.7$, respectively. However, when $40 \mathrm{mM}$ tannic acid was added into above reaction, activity was significantly inhibited to $62.2 \pm 0.3$ and $54.5 \pm 1.1$, respectively. It suggested that $40 \mathrm{mM}$ tannic acid inhibited activity of proteases in midgut juice of $S$. exigua. Among serine proteases included in midgut juice of $S$. exigua in which inhibitory effect of Tannic acid was shown, trypsin had the highest activity, but other three enzymes did not exhibit any significant difference (Fig. 1). As a result, it was found that the activity for a substrate in midgut juice of $S$. exigua was inhibited by about $30-40 \%$ when it was treated with $40 \mathrm{mM}$ tannic

Table 1. Effect of tannic acid on protease activity of $S$. exigua midgut juice

\begin{tabular}{ccc}
\hline Protease inhibitor & $\begin{array}{c}\text { Working concentration } \\
\text { of inhibitor }(\mathrm{mM})\end{array}$ & $\begin{array}{c}\text { Protease activity } \\
\text { (\% control) }\end{array}$ \\
\hline \multirow{2}{*}{ Tannic acid } & 20 & $83.1 \pm 2.1$ \\
& 40 & $77.6 \pm 1.6$ \\
80 & $68.0 \pm 0.4$ \\
& & $40.1 \pm 2.2$ \\
\hline
\end{tabular}


Table 2. Estimation of proteolytic activity in extracts from $S$. exigua midgut with the substrates of various proteolytic enzymes

\begin{tabular}{lcc}
\hline \multicolumn{1}{c}{ Substrate } & Midgut & \multirow{2}{*}{ Protease } \\
\cline { 2 - 2 } & Protease activity (\% control) & Serine \\
Azocasein & $100 \pm 0$ & Trypsin \\
N- $\alpha$-Benzoyl-DL-arginine 4-nitroanilidehydrochloride (BApNA) & $91.4 \pm 1.8$ & \\
N-Benzoyl-Phe-Val-Arg-p-nitroanilidehydrochlorid (BPVApNA) & $89.4 \pm 0.7$ & Chymotrypsin \\
N-Benzoyl-L-tyrosine p-nitroanilide (BTpNA) & $55.4 \pm 0.6$ & \\
N-Succinyl-Ala-Ala-Pro-Phe p-nitroanilide (SAAPPpNA) & $56.5 \pm 3.9$ & Elastase \\
Ala-Ala-Val-Ala p-nitroanilide (AAVApNA) & $52.7 \pm 1.5$ & $48.5 \pm 1.6$ \\
N-Succinyl-Ala-Ala-Ala-p-nitroanilide (SAAApNA) & $38.7 \pm 4.9$ & \\
N-Succinyl-Ala-Ala-Pro-Leu p-nitroanilide (SAAPLpNA) & & \\
\hline
\end{tabular}

Table 3. Inhibitor analysis of proteolytic activity with various substrates of extracts from $S$. exigua midgut

\begin{tabular}{|c|c|c|c|c|c|c|c|}
\hline \multirow{2}{*}{ Inhibitor } & \multirow{2}{*}{$\begin{array}{l}\text { Concentration } \\
(\mathrm{mM})\end{array}$} & \multirow{2}{*}{$\frac{\text { Azocasein }}{\text { Serine }}$} & BApNA & BPVApNA & BTpNA & SAAPPpNA & \multirow{2}{*}{$\begin{array}{c}\text { SAAApNA } \\
\text { Elastase }\end{array}$} \\
\hline & & & \multicolumn{2}{|c|}{ Trypsin } & \multicolumn{2}{|c|}{ Chymotrypsin } & \\
\hline \multirow{4}{*}{ Tannic acid } & 10 & 100 & $86.9 \pm 1.2$ & $87.1 \pm .07$ & $88.9 \pm 1.2$ & $62.3 \pm 1.9$ & $42.5 \pm 0.7$ \\
\hline & 20 & 100 & $83.5 \pm 0.7$ & $81.2 \pm 1.3$ & $86.2 \pm 2.5$ & $51.2 \pm 2.3$ & $44.2 \pm 2.7$ \\
\hline & 40 & 100 & $62.2 \pm 0.3$ & $54.5 \pm 1.1$ & $61 \pm 1.5$ & $51.4 \pm 2.5$ & $46.1 \pm 1.0$ \\
\hline & 80 & 100 & $61.4 \pm 2.1$ & $63.3 \pm 0.5$ & $57.3 \pm 2.1$ & $46.8 \pm \pm 1.2$ & $42.5 \pm 0.7$ \\
\hline
\end{tabular}



Fig. 1. Reductions of proteolytic activities of proteolytic enzymes of $S$. exigua to each substrate with $40 \mathrm{mM}$ tannic acid.

acid. It was known that tannic acid effectively inhibited activity of trypsin among serine proteases.

\section{Digestive roles of midgut juice, trypsin and chymot- rypsin when tannic acid is mixed with protoxin pro- duced by $B$. thuringiensis KB100 strain}

In general, protoxin of $B$. thuringiensis showing insecticidal activity against lepidopteran pests consists of about $130 \mathrm{kDa}$ and it is digested into active toxic protein at $60-70 \mathrm{kDa}$ and a small protein by protease of midgut juice in insects (Li et al., 2011). Therefore, B. thuringiensis KB100 strain exhibited protoxin at $130 \mathrm{kDa}$ and a partially digested protein at $70 \mathrm{kDa}$ (Fig. 2A: lane 1). According to Li et al. (2011), it has been reported that protoxin of $B$. thuringiensis is activated by proteolytic enzymes such as trypsin and chymotrypsin. When protoxin of B. thuringiensis KB100 strain was activated by midgut protease and trypsin, it was broken down into proteins at $60-70 \mathrm{kDa}$ over time. Activation of protoxin of $B$. thuringiensis KB100 strain by midgut juice, trypsin $(0.1 \mathrm{mg} / \mathrm{ml})$ and chymotrypsin $(0.1 \mathrm{mg} / \mathrm{ml})$ was compared (Fig. 2A). Protoxin broken down by midgut juice exhibited a pattern lower than $65 \mathrm{kDa}$ (Fig. 2A: lane 2). The digestion ratio by Trypsin and chymotrypsin was smaller than that by midgut juice. When protoxin was digested by trypsin, it exhibited a protein band at

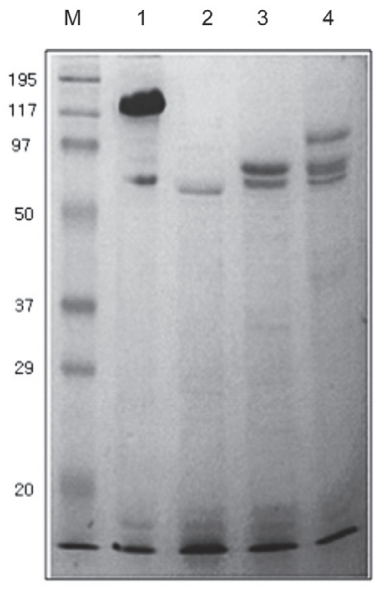

(A)

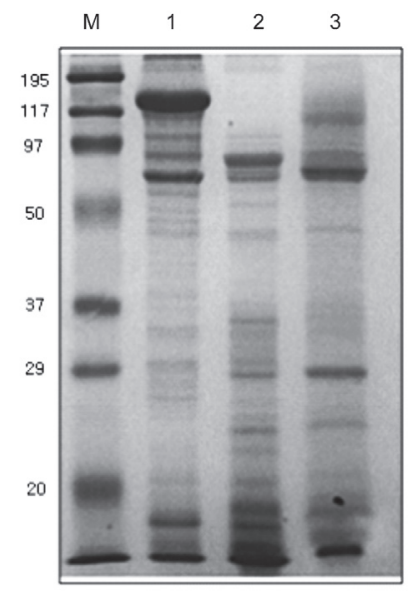

(B)
Fig. 2. (A) Digestion of protoxin by purified trypsin, chymotrypsin, and midgut juice from S. exigua. M: Standard Marker; lane 1: KB100 protoxin; lane 2: midgut juice; lane 3: trypsin; lane 4; chymotrypsin; (B) Effect of tannic acid on the protoxin activation in $S$. exigua midgut juice. M: Standard Marker; lane 1: KB100 protoxin; lane 2: trypsin; lane 3: trypsin+40 mM tannic acid. 
60-70 kDa. When protoxin was digested by chymotrypsin, it exhibited several protein bands at $60-90 \mathrm{kDa}$ (Fig. 2A: Lanes 3, 4). On the basis of previous results, we examined the digestion pattern of protoxin when $40 \mathrm{mM}$ tannic acid was mixed with trypsin in order to determine whether tannic acid inhibited the digestion activity of trypsin when it was mixed with trypsin (Fig. 2B). It was found that activity of trypsin was inhibited when protoxin was decomposed by Trypsin together with $40 \mathrm{mM}$ tannic acid rather than when it was digested by trypsin alone (Fig. 2B: lanes 2, 3). It could be expected that decomposition of protoxin was inhibited when $40 \mathrm{mM}$ tannic acid was mixed with trypsin.

\section{Tannic acid inhibiting the trypsin's role of over- digesting protoxin produced by $B$. thuringiensis KB100 strain}

To compare the degree of decomposition of protoxin in $B$. thuringiensis KB100 strain by various kinds of digestive enzymes, SDS-PAGE was performed after it was treated in each condition. After B. thuringiensis KB100 protoxin was digested with midgut juice of $S$. exi-

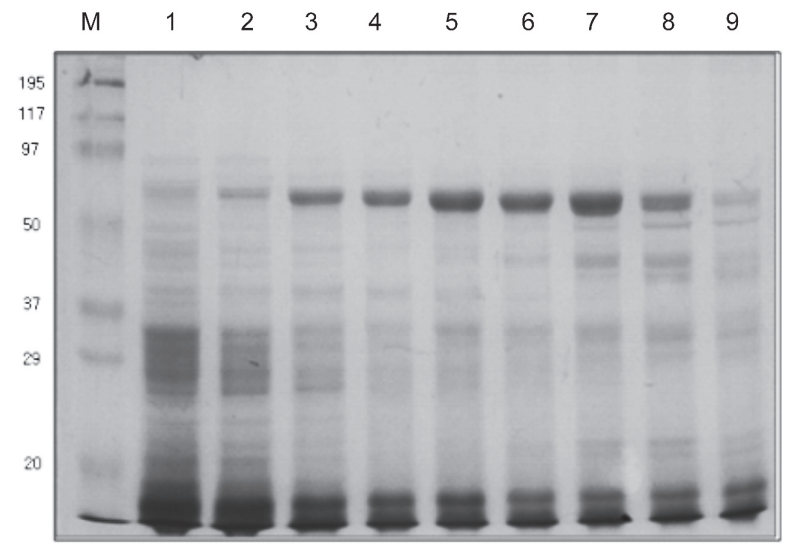

Fig. 3. Effects of incubation time of $S$. exigua midgut juice on KB100 toxin activation. M: Standard marker; lane 1: $1 \mathrm{~min}$; lane 2: $5 \mathrm{~min}$; lane 3: $10 \mathrm{~min}$; lane 4: $15 \mathrm{~min}$; lane 5: $30 \mathrm{~min}$; lane 6: $1 \mathrm{~h}$; lane 7: $2 \mathrm{~h}$; lane 8: $5 \mathrm{~h}$, lane 9: $24 \mathrm{~h}$.

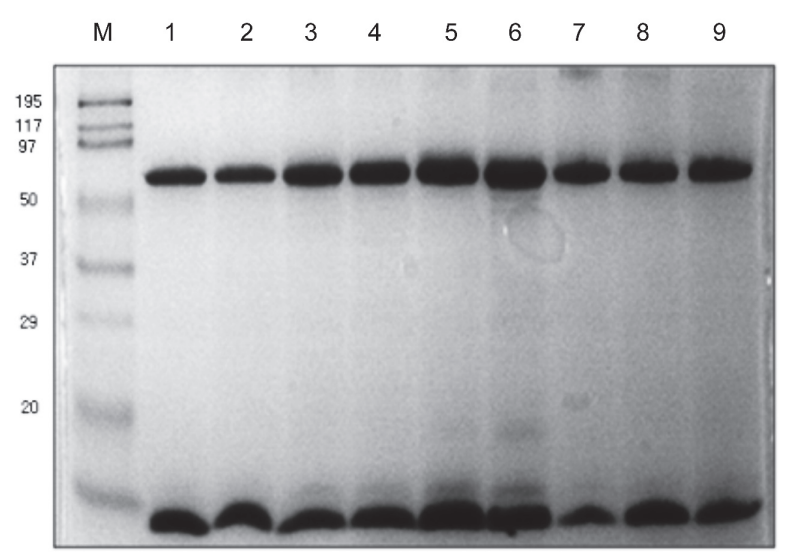

Fig. 4. Effects of incubation time of $40 \mathrm{mM}$ tannic acid on KB100 toxin activation. M: Standard Marker; lane 1: 1min; lane 2: $5 \mathrm{~min}$; lane 3: $10 \mathrm{~min}$; lane 4: $15 \mathrm{~min}$; lane 5: $30 \mathrm{~min}$; lane 6: $1 \mathrm{~h}$; lane 7: $2 \mathrm{~h}$; lane 8: $5 \mathrm{~h}$; lane 9: $24 \mathrm{~h}$. gua for 9 time points such as 1 minute, 5 minutes, 10 minutes, 15minutes, 30 minutes, 1 hour, 2 hours, 5 hours and 24 hours, protein patterns were examined. A band of protein at $60 \mathrm{kDa}$ appeared on SDS-PAGE for up to 5 hours of treatment. The intensity of a band began to be reduced and a band almost disappeared at 24 hours (Fig. 3: lanes 1-9). Thus, it suggested that toxicity of $B$. thuringiensis showing high insecticidal activity against $S$. exigua may not appear in the presence of midgut proteases after pests eat it.

Thus, SDS-PAGE was performed to determine changes of protoxin of $B$. thuringiensis KB100 strain when it was digested by midgut juice together with tannic acid over time (Fig. 4). It was found that a band of protein with insecticidal activity at $60 \mathrm{kDa}$ did not appear and activity was maintained in the sample combined with midgut juice $+B$. thuringiensis $\mathrm{KB} 100+40 \mathrm{mM}$ tannic acid showing the highest synergistic effect in a test of insecticidal activity against $S$. exigua (Fig. 4: lanes 1-9). It was similar to the previous results reporting that tannic acid inhibited the over-digestion of protoxin in $B$. thuringiensis KB100 strain by protease in midgut of $S$. exigua (Jin et al., 2009). In this experiment, a band of toxic protein at $60 \mathrm{kDa}$ showing insecticidal activity against $S$. exigua was constantly maintained for up to 48 hours. In addition, a digestion pattern was examined over time after $B$. thuringiensis KB100 strain was digested by trypsin (Fig. 5). B. thuringiensis KB100 strain began to be digested over time after it was treated with trypsin. After 24 hours, a band of toxic protein at $60 \mathrm{kDa}$ seemed lighter. On the other hand, changes of B. thuringiensis KB100 strain were observed over time when it was treated by trypsin together with tannic acid (Fig. 6). SDS-PAGE analysis exhibited that the digestion process of protoxin of B. thuringiensis KB100 strain by trypsin was inhibited by tannic acid. Therefore, it was found that decomposition rate of protoxin was substantially reduced with addition of tannic acid and its insecticidal activity lasted.

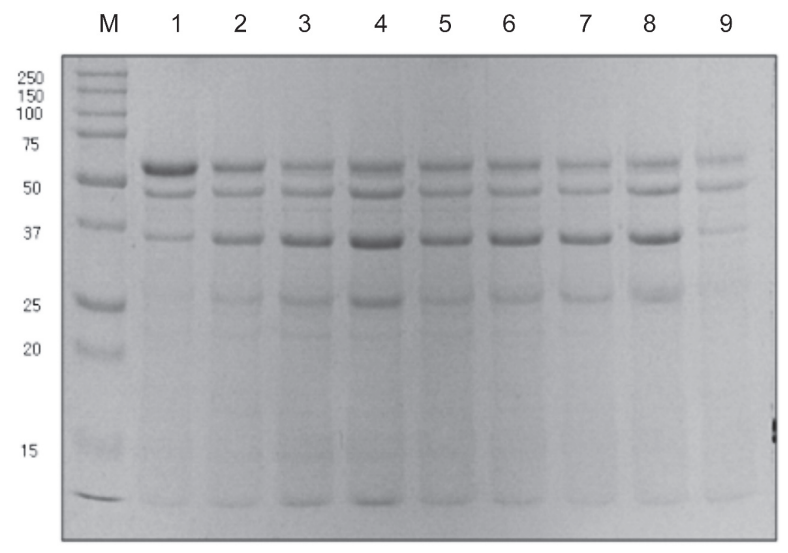

Fig. 5. Effects of incubation time of $S$. exigua midgut juice on typsin. M: Standard marker; lane 1: $1 \mathrm{~min}$; lane 2: $5 \mathrm{~min}$; lane 3: $10 \mathrm{~min}$; lane 4: $15 \mathrm{~min}$; lane 5: $30 \mathrm{~min}$, lane 6: $1 \mathrm{~h}$; lane 7: $2 \mathrm{~h}$; lane 8: $5 \mathrm{~h}$, lane 9: $24 \mathrm{~h}$. 


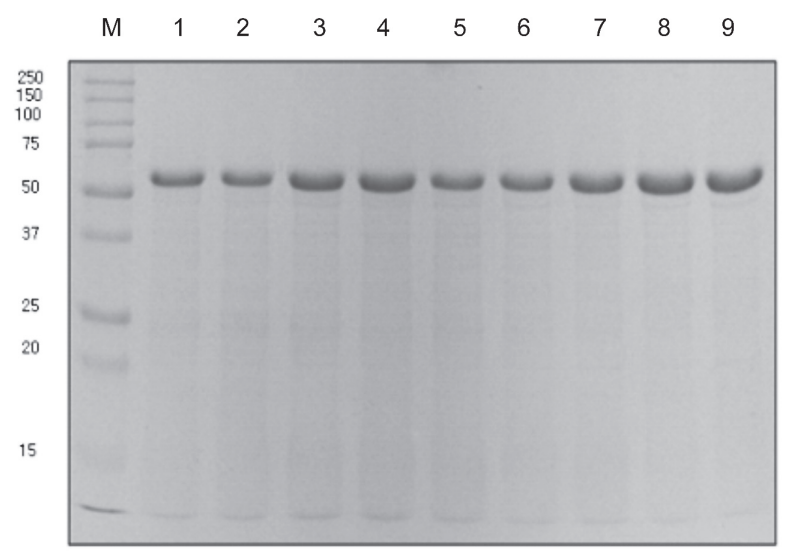

Fig. 6. Effects of incubation time of $40 \mathrm{mM}$ tannic acid on trypsin. M: Standard marker; lane 1: 1 min; lane 2: 5 min; lane 3: $10 \mathrm{~min}$; lane 4: $15 \mathrm{~min}$, lane 5: $30 \mathrm{~min}$; lane 6: $1 \mathrm{~h}$; lane 7: $2 \mathrm{~h}$; lane 8: $5 \mathrm{~h}$; lane 9: $24 \mathrm{~h}$.

\section{ACKNOWLEDGEMENTS}

This paper was written on the basis of results obtained while on-farm technology project (control of moths using entomopathogenic bacteria, project number: PJ010029) was being performed.

\section{REFERENCES}

Ahn, S. B., I. S. Kim, W. S. Cho, M. H. Lee and K. M. Choi 1989 The Occurence of the crop insect pests from Korea in 1988. Korean J. Appl. Entomol. 28: 246-253

Ananthakrishnan, T. N., R. S. Anadurai, R. Senrayan and S. Murugesan 1990 Differential impact of tannic acid and pyrogallol on nutrition and reproduction of two co-existing pests, Heliothis armigera (Hübner) and Spodoptera litura (Fabricius). Phytophyta 3: 55-70

Bradford, M. M. 1976 A rapid and sensitive method for the quantitation of microgram quantities of protein utilizing the principle of protein-dye binding. Anal. Biochem. 72: 248-254

Chan B. G., A. C. Jr Waiss and M. Lukefahr 1978 Condenced tannin, an antibiotic chemical from Gossypium hirsutum. J. Insect Physiol. 24: 113-118

De Maagd, R. A., A Bravo, C Berry, N. Crickmore and H. E. Schnepf 2003 Structure, diversity, and evolution of protein toxins from spore-forming entomopathogenic bacteria. Annu. Rev. Genet. 37: 409-433

Eveleens, K. G., R. Van Den Bosch and L. E. Ehler 1973 Secondary outbreak induction of beet armyworm by experimental insecticide application in cotton in California. Entomol. 2: 497-503

Goh, H. G., S. G. Lee, B. P. Lee, K. M. Choi and J. H. Kim 1990 Simple mass-rearing of beet armyworm, Spodoptera exigua (Hübner) (Lepidoptera: Noctuidae), on an artificial diet. Korean J. Appl. Entomol. 29: 180-183

Jin, N. Y., S. Y. Jung, C. Park, S. K. Paek, M. J. Seo, Y. N. Youn and Y. M. Yu 2009 The synergy effects of mixed treatment with tannic acid and Bacillus thuringiensis subsp. kurstaki KB100 against Spodoptera exigua (Lepidoptera: Noctuidae). Korean J. Appl. Entomol. 48: 519-526

Jongsma, M. A., S. J. Perter, W. J. Stickema and D. Bosch 1996 Characterization and partial purification of gut pretenses of Spodoptera exigua Hübner (Lepidoptera: Noctuidae). Insect biochem. 26: 185-193

Karowe D. N. 1989 Differential effect of tannic acid on two treefeeding Lepidoptera: implication for theories of plant antiherbivore chemistry. Oecologia 80: 507-512

Klocke J. A. and B. G. Chan. 1982 Effect of cotton condenced tannin in feeding and digestion of the cotton pest, Heliothis zea. J. insect Physiol. 28: 911-915

Kumar, P. A. 2003 Insect pest-resistant transgenic crops. In "Advances in Microbial Control of Insect Pest," ed. by R. K. Upadhyay, Kluwer Academic, New York, pp. 71-142

Laemmli, U. K. 1970 Cleavage of structural proteins during the assembly of the head of bacteriophage T4. Nature 277: 680 685

Law, J. H., P. E. Dunn and K. J. Krammer. 1977 Insect proteases and peptidases. Adv. Enzymol. 45: 389-425

Li, H., N. P. Chougule and B. C. Bonning. 2011 Interaction of the Bacillus thuringiensis delta endotoxins Cry1Ac and Cry3Aa with the gut of the pea aphid, Acyrthosiphon pisum (Harris). J. Invertebr. Pathol. 107: 69-78

Lord, J. C. and Undeen A. H. 1990 Inhibition of the Bacillus thuringiensis var. israelensis toxin by dissolved tannins. Environmental Entomology 19: 1547-1551

Luo, L. Z., Y. Z. Cao and X. F. Jiang. 2000 The study on occurrence characteristics and trend of beet armyworm. Plant Protection 26: 37-39

Morris O. N., V. Converse and P. Kanagaratnam. 1995 Chemical additive effects on the efficacy of Bacillus thuringiensis Berliner subsp. kurstaki against Mamesta configurata (Lepidoptera: Noctuidae). J. Economic Entomol. 88: 815-824

Navon A., J. D. Hare and B. A. Federici. 1993 Interactions among Heliothis virescens larvae, cotton condensed tannin and the Cry1A(c) $\delta$-endotoxin of Bacillus thuringiensis. J. Chemical Ecol. 19: 2485-2499

Noh, M. Y. 2009 Cloning and characterization of immune-related genes from the beet armyworm, Spodoptera exigua. The Graduate school, Chonnam National University.

Opprert, B. 1999 Protease interaction with Bacillus thurigiensis insecticidal toxin. Arch. Insect Biochem. Physiol. 42: 1-12

Park, J. D., H. G. Goh, J. H. Lee, W. J. Lee and K. J. Kim. 1991 Flight activity and injury characteristics of beet armyworm, Spodoptera exigua (Hübner), (Lepidoptera: Noctuidae) in Southern Region of Korea. Korean J. Appl. Entomol. 30: 124129

Salama H. S., F. M. Soda and A. Sharaby. 1984 Novel biochemical avenues for enhancing Bacillus thuringiensis endotoxin potency against Spodoptera littoralia. Entomophaga $\mathbf{2 9}$ $171-178$

Schnepf, E., N. Crickmore, J. Van Rie, D. Lereclus, J. Baum, J. Feitelson, D. R. Zeigler and D. H. Dean. 1998 Bacillus thuringiensis and its pesticidal crystal proteins. Microbiol. Mol. Biol. Rev. 62: 775-806

Soberon, M., S. S. Gill and A. Bravo. 2009 Signaling versus punching hole: How do Bacillus thuringiensis toxins kill insect midgut cells. Cell Mol. Life Sci. 66: 1337-1349

Tojo, A and K. Aizawa. 1983 Dissolution and degradation of Bacillus thuringiensis delta-endotoxin by gut juice protease of the silkworm Bombyx mori. Appl. Environ. Microbiol. 45: $576-580$

van Frankenhuyzen, K. 2009 Insecticidal activity of Bacillus thuringiensis crystal proteins. J. Invert. Pathol. 101: 1-16

Zhu Y. C., C. A. Abel and M. S. Chen. 2007 Interaction of Cry1Ac toxin (Bacillus thuringiensis) and proteinase inhibitors on the growth, development, and midgut proteinase activities of the bollworm, Helicoverpa zea. Pestic. Biochem. Physiol. 87: $39-46$ 